\title{
HERNIORRHAPHY AND HERNIOPLASTY- THEIR RELEVANCE AS HERNIA REPAIR TECHNIQUES IN RURAL SETUP: A PROSPECTIVE STUDY
}

\author{
P. Baviskar1 ${ }^{1}$ H. G. Vyas $^{2}$, Kiran Koundinya ${ }^{3}$
}

1Professor, Department of General Surgery, Rural Medical College (A Constituent of Pravara Institute of Medical Sciences: Deemed University), Loni, Maharashtra.

2Professor, Department of General Surgery, Rural Medical College (A Constituent of Pravara Institute of Medical Sciences: Deemed University), Loni, Maharashtra.

${ }^{3}$ Postgraduate Student, Department of General Surgery, Rural Medical College (A Constituent of Pravara Institute of Medical Sciences: Deemed University), Loni, Maharashtra.

ABSTRACT
BACKGROUND
Prospective studies and Meta-analysis have indicated that non-mesh repair is inferior to mesh repair based on recurrence rates in
inguinal hernia. The incidence of complications immediately and later in postoperative period in either of the repairs are also less
in the mesh repairs as compared to the non-mesh repairs.

\section{MATERIALS AND METHODS}

Non-randomised controlled trial of 50 inguinal hernia repairs was conducted in Rural Hospital, Medical College, Loni (Ahmednagar). The subject of study was comparison between herniorrhaphy and hernioplasty as inguinal hernia repair techniques in rural setup. The sample size was considered on Convenience. The cases of inguinal hernias which were complicated with complaints of irreducibility, obstruction, strangulation and gangrene were excluded. All paediatric age group presentations of inguinal hernia were excluded. Only those cases of adult inguinal hernias of uncomplicated variety in the age group of 20 to 70 years were selected for surgery. Cases were allocated for Herniorrhaphy and Hernioplasty alternatively.

Materials used were as below-

1. A polypropylene (Prolene) non-absorbable suture material; size \#1 was used for herniorrhaphy technique.

2. A monofilament polypropylene (Prolene) non-absorbable synthetic knitted surgical mesh, of sizes 3" x 6" and 2" x 4" was used for hernioplasty technique.

Followup was done by physical examination in the outpatient clinic after 1 week, 1 and 6 months and at 1 year.

\section{RESULTS}

In the early phase of recovery of patients who underwent herniorrhaphy, only pain (60\%) and seroma formation (16\%) were seen. Among the other subjects who underwent hernioplasty, pain (16\%) was the only seen complication. No other complications like nerve injury, division of vas, genital oedema, orchitis, testicular atrophy, hydrocoele, aspiration pneumonia, urinary retention, venous phlebitis, or seroma formation were encountered. In subsequent followup for a period of 1 year, neither pain, recurrence nor any prosthesis-related complications were noted in any of the individuals.

\section{CONCLUSION}

Hernia repair with mesh is associated with lesser incidence of complications than herniorrhaphy. Repair of direct hernia has less complications than indirect hernia. The rate of complications in direct hernia (Pain \& seroma) is less with hernioplasty as compared to herniorrhaphy. In indirect hernia repairs, the incidence of seroma formation is not affected by hernioplasty or herniorrhaphy.

\section{KEYWORDS}

Herniorrhaphy, Hernioplasty, Prolene Mesh, Seroma, Pain, Recurrence.

HOW TO CITE THIS ARTICLE: Baviskar P, Vyas HG, Koundinya K. Herniorrhaphy and hernioplasty- Their relevance as hernia repair techniques in rural setup: A prospective study. J. Evolution Med. Dent. Sci. 2018;7(02):194-198, DOI: $10.14260 /$ jemds/2018/43

\section{BACKGROUND}

The surgical treatment of an inguinal hernia dates back to the first century. Formal description of hernia repairs did not appear until the fifteenth century.

'Financial or Other Competing Interest': None.

Submission 27-11-2017, Peer Review 22-12-2017,

Acceptance 28-12-2017, Published 08-01-2018.

Corresponding Author:

Dr. H. G. Vyas,

Professor, Department of General Surgery,

Rural Medical College, Loni, Ahmednagar, Maharashtra.

E-mail: premharidpac@yahoo.co.in

DOI: $10.14260 /$ jemds $/ 2018 / 43$
In 1881, a French surgeon, Lucas-Championniere, performed high ligation of an indirect inguinal hernia sac at the internal ring with primary closure of the wound.

Eduardo Bassini (1844-1924) is considered to be the father of modern inguinal hernia surgery. He incorporated antisepsis, anaesthesia and construction of the inguinal floor along with high ligation of the hernia sac. He was able to substantially reduce morbidity. (Herniorrhaphy is still valid today!). It is universally agreed that this concept was responsible for the modern surgical era of inguinal hernia. The operation was considered the gold standard for inguinal hernia repair for most of the twentieth century. 
Bassini's operation has lost some popularity because of the widespread acceptance of the concept of avoiding tension during herniorrhaphy, championed by Lichtenstein.

Lichtenstein, 1984 [tension-free] repair, theorised that by using mesh prosthesis to bridge the hernia defect rather than closing it with sutures, tension is avoided, He also felt that the lack of tension reduced the incidence of suture pull-out, which would result in a lower recurrence rate.(1)

\section{Aims \& Objectives}

1. To study the comparison between herniorrhaphy using Prolene sutures and hernioplasty using Prolene mesh as repair techniques in cases of inguinal hernias.

2. Efficacy of repair techniques. General complications, local complications and the incidence of recurrence was evaluated with regards to each respective type of hernia repair.

\section{MATERIALS AND METHODS}

A non-randomised controlled trial of inguinal hernia repair was conducted from May 2005 to December 2007 during which period 50 cases were included in the study. The subject of study was comparison between herniorrhaphy and hernioplasty as inguinal hernia repair techniques in rural setup. The Sample size was considered on Convenience.

The patients who approached General Surgery Outpatient Department of Pravara Hospital, Loni during the above given period were selected for surgery. The cases of inguinal hernias which were complicated with complaints of irreducibility, obstruction, strangulation and gangrene were excluded. All paediatric age group presentations of inguinal hernia were excluded. Only those cases of adult inguinal hernias of uncomplicated variety in the age group of 20 to 70 years were selected for surgery. Cases were allocated alternately to the groups comprising Herniorrhaphy and Hernioplasty. Cases other than inguinal hernias were not included in the study.

\section{Materials used were as below-}

1. A polypropylene (Prolene) non-absorbable suture material; size \#1 was used for herniorrhaphy technique.

2. A monofilament polypropylene (Prolene) non-absorbable synthetic knitted surgical mesh, of sizes 3" x 6" and 2" x 4 " was used for hernioplasty technique.

All relevant investigations were done and anaesthesia fitness taken prior to surgery. Surgery was done by single team for both the types of cases. The patients were subsequently followed up in the ward until discharge from the hospital. After discharge, followup was done in the outpatient clinic on a regular basis, after 1 week, 1 and 6 months and at 1 year.

Patients were asked whether they have suffered a recurrence, COPD, obstipation, prostate disease or obesity. Patients were invited to visit the outpatient clinic, where a history was taken and a physical examination was conducted. The groin region was examined physically for recurrence of inguinal hernia.

During each examination, following observations were made in both the groups.

\begin{tabular}{|c|c|c|c|c|c|c|}
\hline $\begin{array}{c}\text { Complications } \\
\text { Related to }\end{array}$ & Operative & $\mathbf{Y} / \mathbf{N}$ & Early & $\mathbf{Y} / \mathbf{N}$ & Late & $\mathbf{Y} / \mathbf{N}$ \\
\hline Incision & $\begin{array}{c}\text { Bruising \& } \\
\text { Haematoma }\end{array}$ & Infection & $\begin{array}{c}\text { Chronic } \\
\text { sepsis \& } \\
\text { sinus } \\
\text { formation }\end{array}$ & \\
\hline Scrotum & & $\begin{array}{c}\text { Genital } \\
\text { Oedema, } \\
\text { Orchitis\& } \\
\text { Atrophy }\end{array}$ & & & \\
\hline $\begin{array}{c}\text { Open } \\
\text { technique }\end{array}$ & $\begin{array}{c}\text { Nerve } \\
\text { Injuries }\end{array}$ & $\begin{array}{c}\text { Injuries } \\
\text { to the vas }\end{array}$ & $\begin{array}{c}\text { Extrocoele } \\
\text { ordinary } \\
\text { Pain }\end{array}$ & Recurrence & Pain & \\
\hline & $\begin{array}{c}\text { Seroma } \\
\text { Systemic } \\
\text { anaesthesia } \\
\text { Complications }\end{array}$ & $\begin{array}{c}\text { Chest } \\
\text { Infection }\end{array}$ & & & \\
\hline & $\begin{array}{c}\text { Local } \\
\text { Anaesthesia } \\
\text { Complications }\end{array}$ & $\begin{array}{c}\text { Urinary } \\
\text { Retention }\end{array}$ & & & \\
\hline & $\begin{array}{c}\text { Venous } \\
\text { Thrombosis }\end{array}$ & & & \\
\hline
\end{tabular}

The data collected were compared with different groups. The statistical analysis was done using Chi-Square Test.

\section{OBSERVATION}

Among 25 subjects who underwent Bassini's herniorrhaphy, the age group ranged between 20 to 70 years. 7 direct, 18 indirect, 6 bilateral ( 4 direct, and 2 indirect), and 1 pantaloon hernia were encountered.

\section{Statistical Calculations}

The main complications arising from different hernia repairs in our group are pain and seroma formation, seen as early complication of surgery. Hence, the statistical implication of the comparative data is limited to these two complications seen over the period of study in 50 individuals over a 3-year period. The statistical method used was Chi Square Test. Half of the individuals underwent herniorrhaphy and the other half underwent hernioplasty as the choice of hernia repair. In bilateral hernias, the individual underwent different repairs on either side. No complicated or congenital hernias were included in the study. The age limit was kept between 20-70 yrs. The type of hernia, viz, direct or indirect was not taken as the criteria for selection of either the patient or the repair. The Bassini's herniorrhaphy was chosen as the method of herniorrhaphy. Similarly, the Lichtenstein tension-free hernioplasty with a Prolene hernia mesh (3" x 6") was chosen as the hernioplasty technique.

Following are the comparative data for the above study with various parameters taken into consideration after completion of study along with the Chi-square test performed in each of them for establishing the correlation of the parameters with the seen complication.

\begin{tabular}{|c|c|c|c|c|}
\hline Procedure & Pain & No Pain & Total & Pain Rate \% \\
\hline Herniorrhaphy & 15 & 10 & 25 & $60 \%$ \\
\hline Hernioplasty & 4 & 21 & 25 & $16 \%$ \\
\hline Total & $\mathbf{1 9}$ & $\mathbf{1 1}$ & $\mathbf{5 9}$ & \\
\hline Table 1. Comparison of Complications in Inguinal Hernia \\
Repairs \\
\hline
\end{tabular}




\begin{tabular}{|c|c|c|c|c|}
\hline Procedure & Seroma & No Seroma & Total & $\begin{array}{c}\text { Seroma Rate } \\
\mathbf{\%}\end{array}$ \\
\hline Herniorrhaphy & 4 & 21 & 25 & $16 \%$ \\
\hline Hernioplasty & 0 & 25 & $250 \%$ & \\
\hline Total & $\mathbf{4}$ & $\mathbf{4 6}$ & $\mathbf{5 0}$ & \\
\hline
\end{tabular}

For pain, the $\mathrm{X}^{2}=10.27$ and for seroma, the $\mathrm{X}^{2}=4.34$, for d.f. $=1$ and $p-0.05$ which is greater than 3.84 the value of $p$ 0.05 at d.f. $=1$ suggesting a correlation between the choice of hernia repair and the occurrence of the seen complications. From the above available data, hernioplasty has a significant low rate of complication occurrence than herniorrhaphy.

\begin{tabular}{|c|c|c|c|c|}
\hline Hernia & Pain & No pain & Total & $\begin{array}{c}\text { Pain rate } \\
\%\end{array}$ \\
\hline Direct & 3 & 25 & 28 & 10.71 \\
\hline Indirect & 17 & 19 & 36 & 47.22 \\
\hline Total & $\mathbf{2 0}$ & $\mathbf{4 4}$ & $\mathbf{6 4}$ & \\
\hline Table 2. Comparison of Complications in Inguinal Hernia \\
Types \\
\hline
\end{tabular}

\begin{tabular}{|c|c|c|c|c|}
\hline Hernia & Seroma & No seroma & Total & $\begin{array}{c}\text { Seroma } \\
\text { rate \% }\end{array}$ \\
\hline Direct & 3 & 25 & 28 & 10.71 \\
\hline Indirect & 1 & 35 & 36 & 2.77 \\
\hline Total & $\mathbf{4}$ & $\mathbf{6 0}$ & $\mathbf{6 4}$ & \\
\hline
\end{tabular}

For pain, the $X^{2}=9.83$ and for seroma, the $X^{2}=1.73$, for d.f. $=1$ and $\mathrm{p}-0.05$.

For pain, the value is higher than 3.84, the value of $\mathrm{p}-0.05$ at d.f. $=1$ suggesting a correlation between in type of hernia and the occurrence of pain as a complication of repair, irrespective of type. From the available data, direct hernias seem to have lower occurrence of pain as an early postoperative complication of open technique than indirect hernias.

On the contrary, since the value of $\mathrm{X}^{2}$ is less than 3.84 , the value of p- 0.05 for d.f. $=1$, no correlation can be established between seroma formation and the type of hernia repaired irrespective of the type of hernia repair. The type of inguinal hernia does not predispose the patient to the development of seroma formation postoperatively.

\begin{tabular}{|c|c|c|c|c|}
\hline $\begin{array}{c}\text { Direct Hernia } \\
\text { Repair }\end{array}$ & Pain & No Pain & Total & $\begin{array}{c}\text { Pain Rate } \\
\mathbf{\%}\end{array}$ \\
\hline Herniorrhaphy & 3 & 9 & 12 & 25 \\
\hline Hernioplasty & 0 & 16 & 16 & 0 \\
\hline Total & $\mathbf{3}$ & $\mathbf{2 5}$ & $\mathbf{2 8}$ & \\
\hline Table 3. Comparison of Complications in Direct Hernia \\
Repairs
\end{tabular}

\begin{tabular}{|c|c|c|c|c|}
\hline $\begin{array}{c}\text { Direct Hernia } \\
\text { Repair }\end{array}$ & Seroma & $\begin{array}{c}\text { No } \\
\text { Seroma }\end{array}$ & Total & $\begin{array}{c}\text { Seroma } \\
\text { Rate \% }\end{array}$ \\
\hline Herniorrhaphy & 3 & 9 & 12 & 25 \\
\hline Hernioplasty & 0 & 16 & 16 & 0 \\
\hline Total & $\mathbf{3}$ & $\mathbf{2 5}$ & $\mathbf{2 8}$ & \\
\hline
\end{tabular}

For pain and seroma formation, the $\mathrm{X}^{2}=7.14$, for d.f. $=1$ and p-0.05 is higher than 3.84 which suggests a significant correlation between the choice of direct inguinal hernia repair and the occurrence of complications. From the above data, it is very clear that herniorrhaphy has higher rate of complications than hernioplasty in direct hernia repairs.

\begin{tabular}{|c|c|c|c|c|}
\hline $\begin{array}{c}\text { Indirect Hernia } \\
\text { Repair }\end{array}$ & Pain & No Pain & Total & $\begin{array}{c}\text { Pain Rate } \\
\%\end{array}$ \\
\hline Herniorrhaphy & 13 & 10 & 23 & 56.52 \\
\hline Hernioplasty & 4 & 11 & 15 & 26.66 \\
\hline Total & 17 & 21 & 38 & \\
\hline Table 4. Comparison of Complications in Indirect Hernia \\
Repairs
\end{tabular}

\begin{tabular}{|c|c|c|c|c|}
\hline $\begin{array}{c}\text { Indirect Hernia } \\
\text { Repair }\end{array}$ & Seroma & $\begin{array}{c}\text { No } \\
\text { Seroma }\end{array}$ & Total & $\begin{array}{c}\text { Seroma } \\
\text { Rate \% }\end{array}$ \\
\hline Herniorrhaphy & 1 & 22 & 23 & 4.54 \\
\hline Hernioplasty & 0 & 15 & 15 & 0 \\
\hline Total & 1 & 37 & 38 & \\
\hline
\end{tabular}

For pain, the $\mathrm{X}^{2}=3.29$, for d.f. $=1$ and $\mathrm{p}-0.05$, and for seroma formation the $\mathrm{X}^{2}$, for d.f. $=1$ and $\mathrm{p}-0.05$. Since both the values are less than 3.84 , the value for d.f. $=1$ and $p-0.05$, no significant relation between the choice of hernia repair and the occurrence of complications in indirect inguinal hernias can be made. Indirect inguinal hernias do not predispose the occurrence of complications in hernia repair surgery irrespective of type.

\begin{tabular}{|c|c|c|c|c|}
\hline Procedure & Pain & No pain & Total & Pain rate \% \\
\hline Herniorrhaphy & 2 & 4 & 6 & 33.33 \\
\hline Hernioplasty & 1 & 5 & 6 & 20 \\
\hline Total & 3 & 9 & 12 & \\
\hline Table 5. Comparison of Complications of Different Hernia \\
Repairs in Bilateral Hernias of Same Patient \\
\hline
\end{tabular}

\begin{tabular}{|c|c|c|c|c|}
\hline Procedure & Seroma & $\begin{array}{c}\text { No } \\
\text { seroma }\end{array}$ & Total & $\begin{array}{c}\text { Seroma } \\
\text { rate \% }\end{array}$ \\
\hline Herniorrhaphy & 2 & 4 & 6 & 33.33 \\
\hline Hernioplasty & 0 & 6 & 6 & 0 \\
\hline Total & 2 & 10 & 12 & \\
\hline
\end{tabular}

Table 5. Comparison of Complications of Different Hernia Repairs in Bilateral Hernias of Same Patient

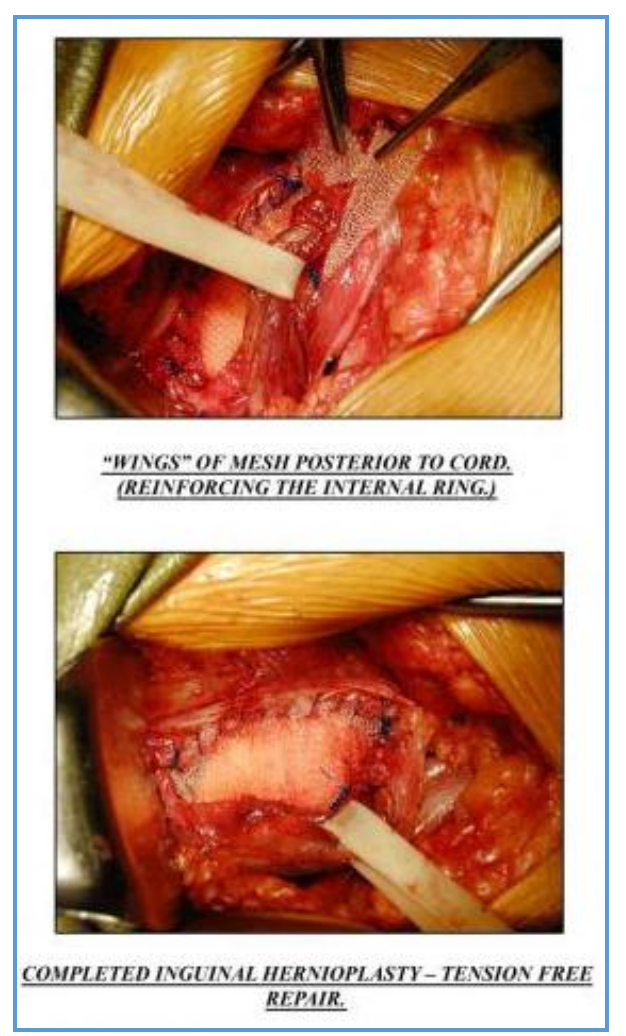



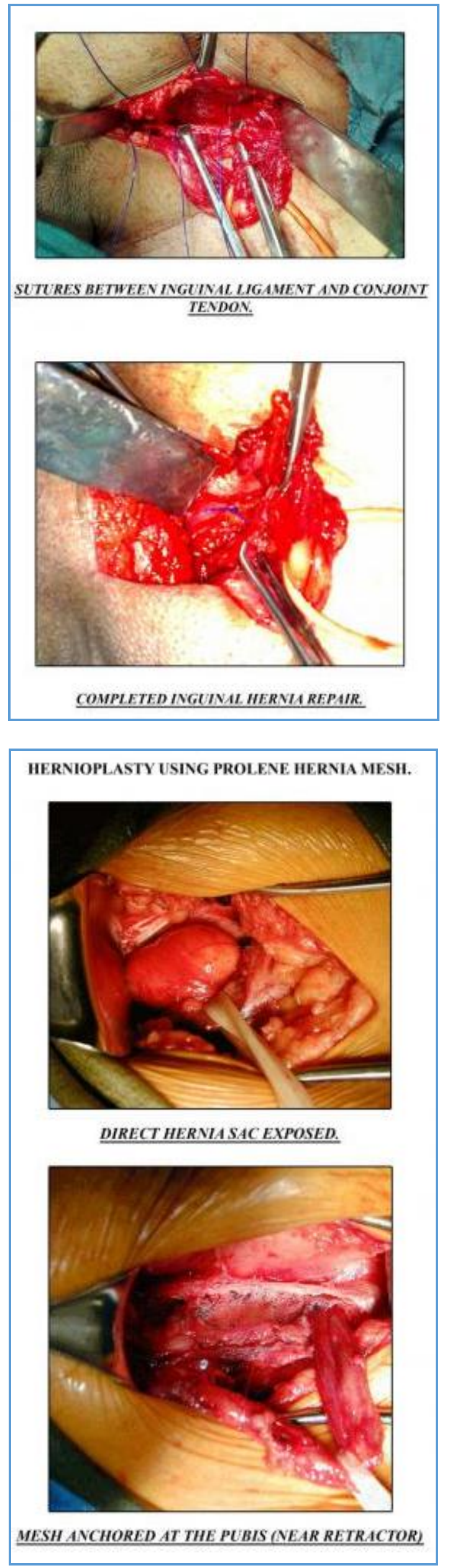

\section{RESULTS}

Among 25 subjects who underwent Bassini's herniorrhaphy, the age group ranged between 20 to 70 years. 7 direct, 18 indirect, 6 bilateral ( 4 direct, and 2 indirect), and 1 pantaloon hernia were encountered. In the early phase of recovery, only pain and seroma formation were seen. 15 out of 25 patients (60\%) experienced pain. The pain was only nociceptive in nature. The pain resolved spontaneously within 2 weeks. None of the patients had symptoms suggestive of neuropathic origin of pain with likely nerve entrapments. Seroma formation was seen in 4 of 25 patients (16\%). The seroma resolved spontaneously over a period of 1 week and did not interfere with wound healing. No intervention was done to remove the seroma formation. No other complications like nerve injury, division of vas, genital oedema, orchitis, testicular atrophy, hydrocoele, aspiration pneumonia, urinary retention, or venous thrombosis were encountered. In subsequent followup for a period of 1 year, neither pain nor recurrence was noted in any of the individual.

Among the other 25 subjects who underwent Lichtenstein's hernioplasty, the age group ranged between 25 to 70 years. 13 direct, 12 indirect, and 6 bilateral $(3$ direct and 3 indirect) hernias were encountered. In the early phase of recovery pain was the only seen complication. Four out of $25(16 \%)$ had postoperative pain which again was only nociceptive in nature. The pain resolved spontaneously with 1-2 weeks with no residue. No nerve entrapment syndromes were encountered. No other complications like nerve injury, division of vas, genital oedema, orchitis, testicular atrophy, hydrocoele, aspiration pneumonia, urinary retention, venous phlebitis, or seroma formation were encountered. In subsequent followup for a period of 1 year neither pain, recurrence nor any prosthesis related complications were noted in any of the individuals.

All patients resumed duties immediately 15 days of postoperative status, and did not seek consultation with regards to the inguinal hernia repaired. Their response to postoperative followup for a long period of 1 year was satisfactory. We did not encounter any recurrence in our entire study in any of the repairs.

\section{DISCUSSION}

The study has provided evidence that mesh repair of inguinal hernia is superior to non-mesh repair. Though hernias may recur over periods of up to 10 years after conventional hernia surgery, the recurrence rates are influenced not only by surgical expertise and method of repair, but also by the duration and method of followup.

Results summarised by the EU Hernia Trialists Collaboration suggest a $60 \%$ decrease in relative risk of recurrence with the use of synthetic meshes compared to the conventional surgery.(3) Use of synthetic meshes reduces the risk of groin hernia recurrence by around 50 percent, regardless of the method of placement. $(3,4)$

Lichtenstein and colleagues established the basis for current inguinal hernia surgery and reported no recurrences among 1000 consecutive patients followed up for 1-5 years after primary mesh repair. Excluding the patient in this study who received a resorbable mesh, the present recurrence rate was also zero and was comparable to that in other studies describing low recurrence rates. $(5,6,7)$ 
The Lichtenstein tension-free mesh repair opened a new era in groin hernia repair. Without the risk of serious morbidity, it is now readily performed using local anaesthesia in patients previously considered unsuitable for surgery. Fears of serious complications related to mesh implantation have proved to be without foundation.

\section{Limitations}

Relatively small sample size, unrepresentative, nonrandomised study. Large, randomised, double blind, multicentre studies are needed to remove the bias and have external validity.

\section{CONCLUSION}

Our study found that hernioplasty is associated with less incidence of complications than compared with operation of herniorrhaphy. Pain and seroma formation were encountered as main complications in hernia operations. Repair of direct hernia has less incidence of complications compared to repair of direct hernias. In direct hernia, the repair by hernioplasty is associated with less incidence of complications than when hernia is repaired by herniorrhaphy. The incidence of seroma formation is not influenced by type of operation in indirect inguinal hernia. In indirect hernia repairs, herniorrhaphy is associated with higher complications than hernioplasty.

\section{REFERENCES}

[1] Simons MP, Kleijnen J, Van Geldere D, et al. Role of the Shouldice technique in inguinal hernia repair: a systematic review of controlled trials and a metaanalysis. Br J Surg 1996;83(6):734-8.

[2] Srinivasan A, Schuricht A. Long-term followup of laparoscopic preperitoneal repair in professional athletes. J Laparoendosc Adv Surg Tech A 2002;12(2):101-6.

[3] Scott NW, McCormack K, Graham P, et al. Open mesh versus non - mesh for repair of femoral and inguinal hernia. Cochrane Database of Systematic Reviews 2002;(4):CD002197.

[4] Schulman AG, Amid PK, Lichtenstein IL. The safety of mesh repair for primary inguinal hernias: results of 3019 operations from five diverse surgical sources. Am Surg 1992;58(4):255-7.

[5] Wantz GE. Experience with the tension - free hernioplasty for primary inguinal hernias in men. J Am Coll Surg 1996;183(4):351-6.

[6] McGillicuddy JE. Prospective randomized comparison of the Shouldice and Lichtenstein hernia repair procedures. Arch Surg 1998;133(9):974-8. 